\title{
Assessment of the safety and ease of use of the naloxone auto-injector for the reversal of opioid overdose
}

This article was published in the following Dove Press journal:

Open Access Emergency Medicine

8 June 2015

Number of times this article has been viewed

\author{
Mark A Merlin ${ }^{1,2}$ \\ Navin Ariyaprakai' \\ Faizan H Arshad ${ }^{1,2}$ \\ 'Newark Beth Israel Medical Center, \\ Newark, NJ, USA; ${ }^{2}$ Monmouth Ocean \\ Hospital Service Corporation (MONOC), \\ Wall Township, NJ, USA
}

\begin{abstract}
Over the last decade, opioid-related deaths in the United States have increased at an alarming rate. The use of naloxone by laypersons is a newer concept and its utilization can benefit patients by rapid administration due to it being readily available immediately after an opioid overdose. The US Food and Drug Administration approved a naloxone auto-injector on April 3, 2014 for adults and pediatrics, designed for use by anyone including patients, family members, bystanders, and medical professionals. This device (EZVIO $\left.{ }^{\mathrm{TM}}\right)$ is the first device of its kind available on the market. The auto-injector is a battery-operated disposable $0.4 \mathrm{mg} / 0.4 \mathrm{~mL}$ prefilled device for use in the lateral thigh by patients, bystanders, or health care professionals. It utilizes auditory and visual commands for ease of administration and instructs patients to seek further medical care after injection. EVZIO costs about $\$ 600$ for two auto-injectors and a trainer. Additionally, in August 2013, the Substance Abuse and Mental Health Services Administration introduced the Opioid Overdose Toolkit, a federal resource promoting safety and prevention information. This extensive document provides information for medical professionals, first responders, patients, caregivers, and overdose survivors. It outlines many strategies for dealing with this health care crisis. Most importantly, it highlights the importance of rapid recognition and treatment of opioid overdoses as well as routine conversations with patients assessing the need for naloxone prescriptions. The auto-injector is a safe, portable device with limited instruction needed and should routinely be made available to anyone who has contact with an opioid user.
\end{abstract}

Keywords: narcotics, abuse, heroin, EZVIO

\section{Introduction}

Opioid overdoses have become an international health crisis. ${ }^{1}$ Over the last decade, opioid-related deaths in the United States have increased at an alarming rate. There were more than four-times as many opioid fatalities in 2011 than there were in $1999 .^{2}$ Center for Disease Control data for the US demonstrates the age-adjusted rate for opioid-analgesic poisoning deaths went from 1.4 per 100,000 in 1999 to 5.4 per 100,000 in $2011 .^{2}$ In 2012, there were 16,007 deaths due to opioids and 5,925 due to heroin in the US, which equates to two deaths per hour. ${ }^{3}$

Naloxone hydrochloride is a short-acting, non-addictive, opioid antagonist that is used for respiratory or central nervous system depression from opioid overdose. ${ }^{4}$ In 1971, naloxone received US Food and Drug Administration (FDA) approval. Subsequently, it has become the standard first-line agent in the emergency setting for rapid reversal of accidental or intentional opioid overdose.

Previously, naloxone products were only available in glass vials and ampules. They are distributed with syringes and needles for manual injection, or with syringes and
Correspondence: Mark A Merlin Newark Beth Israel Medical Center, 20I Lyons Avenue D-I I, Newark, NJ, USA

Email markamerlin@gmail.com 
atomizers for nasal administration. Nasal administration is not FDA approved but is frequently utilized by emergency personnel. Use of naloxone by trained medical professionals requires minimal additional training and has been the standard of care for opioid overdoses. However, the use of naloxone by laypersons is a newer concept and its utilization can benefit patients by rapid administration due to it being readily available immediately after an opioid overdose. Subsequently, new and improved ways to provide the general public with the ability to utilize naloxone are being sought.

This article reviews the current literature on a new, novel auto-injector available for patients. The review consists of available website and published literature on Medline from 1966 to the present with a cross-reference of one paper from 1963. Search terms utilized were "naloxone", "auto-injector", "opioid", "overdose", and "EZVIO".

\section{New auto-injector}

The FDA approved a naloxone auto-injector on April 3, 2014 for adults and pediatrics, designed for use by anyone including patients, family members, bystanders, and medical professionals. This device (EZVIO ${ }^{\mathrm{TM}}$; Kaleo Pharma, Richmond, VA, USA) is the first device of its kind available on the market. FDA Commissioner Margaret Hamburg called EVZIO "an extremely important innovation". 7 Dr Hamburg noted that EVZIO received its approval almost 10 weeks ahead of schedule. ${ }^{7}$ EVZIO labeling expands the scope of possible prescription recipients to caregivers, which is unusual for an FDA recommendation. Prescribers are encouraged to provide EVZIO to caregivers and others who are likely to witness and reverse an overdose without any professional supervision.

The auto-injector is a battery-operated disposable $0.4 \mathrm{mg} / 0.4 \mathrm{~mL}$ prefilled device for use in the lateral thigh by patients, bystanders or health care professionals which may be injected through clothing if necessary. It is supplied as a two-dose pack with an additional trainer. It utilizes auditory and visual commands for ease of administration and instructs patients to seek further medical care after injection. The device has a protective outer case that is approximately $7.5 \times 5 \mathrm{~cm}$ and is stored at room temperature with an acceptable excursion range between $4^{\circ} \mathrm{C}$ and $40^{\circ} \mathrm{C}$. The needle is a retractable 23 gauge which is not visible during the entire injection process. Because of EVZIO small size, it is easy portable. A trainer device as well as visual and auditory instructions for use when activated is provided in each packet. ${ }^{5}$ The FDA accepted prior epinephrine auto-injector studies to demonstrate the safety and efficacy of the naloxone auto-injector. ${ }^{6,7}$
The FDA required a human factor validation study for approval. ${ }^{8}$ Subjects consisted of 40 English-speaking participants who were asked to use the device without training or reading the guide. The 40 participants consisted of 21 adults and 19 children (aged 12-19 years). Ten percent of participants were unable to adequately deliver the medication to the patient. After analyzing the results, the FDA determined that a person could adequately utilize the device and fast-tracked approval. Approval was based on this study, ${ }^{8}$ but no safety or efficacy studies were required by the FDA. No human factor studies have been conducted in non-English-speaking individuals.

\section{Cost}

EVZIO costs about $\$ 600$ for two auto-injectors and a trainer. Private insurers are currently considering payments. Patient assistance programs are available via Kaleo Pharmaceuticals (http://www.evzio.com).

\section{Access}

Typically throughout the US, prehospital advanced life support personnel provide naloxone to a patient overdosing on opioids, most commonly heroin. However, depending on the region, some basic life support providers (emergency medical technicians) are unable to provide the medication. This depends on regional regulations. Davis et al conducted a national systematic legal review regarding emergency medical services' naloxone access. ${ }^{9}$ They evaluated all 50 states as well as the District of Columbia, Guam, and Puerto Rico in 2013. All 53 jurisdictions permit paramedics to administer naloxone. Of the 48 jurisdictions with intermediate-level emergency medical services personnel, all but one authorize naloxone administration. Twelve jurisdictions allow emergency medical technicians to administer naloxone and two permit general first responders to administer naloxone. This outlines the importance of maintaining the ability for laypersons to inject naloxone since responding ambulances in many jurisdictions will not have this medication. The time delay in medication administration can result in death or anoxic brain injury which may lead to permanent disability. Administration delivery time is the rate-limiting step in an opioid overdose.

\section{Naloxone distribution to the general public}

In 1996, several systems around the country began distributing naloxone to nonmedical professionals with promising results. A program in Chicago was established in 1999 and 
later in New York City in 2005. ${ }^{10}$ These programs require that participants recognize an opioid overdose, assemble medication, and administer medication. ${ }^{11}$ The time and materials for education differ depending on the program. ${ }^{12}$ The delivery of medication can range from intramuscular (IM) to subcutaneous or intranasal. All modalities were generally similar in effectiveness. ${ }^{13-15}$

In the United Kingdom, the N-ALIVE trial is providing naloxone to recently released prisoners who are at the highest risk for opioid overdose with IM medication. ${ }^{16}$ The Staying Alive Overdose Prevention Project in Baltimore, MD utilized a 1-hour training session where participants learned rescue breathing, overdose recognition, and IM medication administration. They found that participants were able to recognize and treat an opioid overdose effectively, using IM naloxone. ${ }^{17}$ In a San Francisco program, patients received 5-10 minutes of education then demonstrated adequate recognition and ability to treat an overdose. ${ }^{18}$ They believed that their community has a high base knowledge of opioid overdose. EVZIO also eliminates any assembly required in naloxone's existing IM or off-label intranasal devices.

\section{Changes in heroin patterns by naloxone availability}

Heroin users do not increase their dose because naloxone is available. They do not want to experience withdrawal precipitated by naloxone. ${ }^{19}$ In one naloxone program for heroin users, the frequency of heroin injection and number of overdoses decreased. ${ }^{20}$ In communities where naloxone-distribution programs exist, opioid overdose deaths decrease. ${ }^{21,22}$ Additionally, there is a perceived medical liability risk among health care providers to prescribe naloxone to third parties. Currently, one-third of states have victim shield laws protecting health care providers. With the FDA recommendation to prescribe to third parties, this may alleviate some fear among providers.

\section{Public awareness of opioid crisis}

Public awareness has increased with the aforementioned programs and layperson distribution of naloxone. Additionally, in August 2013, the Substance Abuse and Mental Health Services Administration introduced the Opioid Overdose Toolkit (http://evzio.com/hcp/about-naloxone/samhsaopioid-overdose-toolkit.php), a federal resource promoting safety and prevention information. ${ }^{23,24}$ This extensive document provides information for medical professionals, first responders, patients, caregivers, and overdose survivors.
It outlines many strategies for dealing with this health care crisis. Most importantly, it highlights the importance of rapid recognition and treatment of opioid overdoses as well as routine conversations with patients in assessing the need for naloxone prescriptions. Ultimately, primary care providers need to complete a thorough social history to determine the need for a naloxone prescription.

\section{Risk of patient injection}

After administration of naloxone, participants are often instructed to seek further medical care depending on the regional program. In Copenhagen, Denmark, medical emergency care units staffed by physicians have been discharging selected patients on-scene after naloxone administration since 1994 with low risk of death due to rebound toxicity. ${ }^{25}$ In San Antonio, TX, USA, 592 patients were treated by paramedics with naloxone and then refused transport; none were found to have died within 48 hours. ${ }^{26}$ In San Diego, CA, USA, 998 patients were treated by paramedics then signed against medical advice with no deaths from those patients in the next 12 hours. ${ }^{27}$

\section{Conclusion}

Opioid abuse has become endemic. The widespread abuse of opioid medications requires society to have a proactive response. The naloxone auto-injector is the first naloxone product designed for use by laypersons in the emergency treatment of known or suspected opioid overdose. The newly approved naloxone auto-injector is easy to use, requires little to no training, and is effective. Rapid dissemination of naloxone is the only effective means to combat the crisis of opioid overdose throughout the world. The auto-injector is a safe, portable device with limited instruction needed and should routinely be made available to anyone who has contact with an opioid user.

\section{Disclosure}

The authors report no conflicts of interest in this work.

\section{References}

1. Facts \& Stats, Stats about international overdose[webpage on the Internet]. International Overdose Awareness Day; 2014. Available from: http:// www.overdoseday.com/facts-stats/. Accessed March 27, 2015.

2. Injury Prevention \& Control: Prescription Drug Overdose [webpage on the Internet]. CDC. Centers for Disease Control and Prevention [cited April 3, 2015]. Available from http://www.cdc.gov/drugoverdose/index. html. Accessed January 2, 2015.

3. Warner, M, Hedegaard, H, Chen, LH. Trends in Drug-Poisoning Deaths Involving Opioid Analgesics and Heroin: United States, 1999-2012. Atlanta: National Center for Health Statistics; 2014. Available from: http://www.cdc.gov/nchs/data/hestat/drug_poisoning/drug_poisoning_ deaths_1999-2012.pdf. Accessed January 20, 2015. 
4. Sadove MS, Balagot RC, Hatano S, Jobgen EA. Study of a narcotic antagonist - N-allyl-noroxymorphone. JAMA. 1963;183:666-668.

5. Kuehn BM. Easy-to-use overdose antidote earns fast-track approval. JAMA. 2014;311(16):1600.

6. Berteau C, Schwarzenbach F, Donazzolo Y, et al. Evaluation of performance, safety, subject acceptance, and compliance of a disposable autoinjector for subcutaneous injections in healthy volunteers. Patient Prefer Adherence. 2010;4:379-388.

7. Center for Drug Evaluation and Research. Summary Review: EVZIO. Silver Spring: US Food and Drug Administration; 2014. Available from: http://www.accessdata.fda.gov/drugsatfda_docs/ nda/2014/205787Orig1s000SumR.pdf. Accessed January 28, 2015.

8. Pharmacy Benefits Management Services. Naloxone Injection (EVZIO, Auto-injector): National PBM Abbreviated Drug Review. Washington (DC): US Department of Veterans Affairs; 2014. Available from: http://www.pbm.va.gov/PBM/clinicalguidance/ abbreviatedreviews/Naloxone_Autoinjector_EVZIO_Abbreviated_ Review_revised_2014_07_16.docx. Accessed January 28, 2015.

9. Davis CS, Southwell JK, Niehaus VR, Walley AY, Dailey MW. Emergency medical services naloxone access: a national systematic legal review. Acad Emerg Med. 2014;21(10):1173-1177.

10. Sporer KA, Firestone J, Isaacs SM. Out-of-hospital treatment of opioid overdoses in an urban setting. Acad Emerg Med. 1996;3(7):660-667.

11. Strang J, Manning V, Mayet S, et al. Overdose training and take-home naloxone for opiate users: prospective cohort study of impact on knowledge and attitudes and subsequent management of overdoses. Addiction. 2008;103(10):1648-1657.

12. Jones JD, Roux P, Stancliff S, Matthews W, Comer SD. Brief overdose education can significantly increase accurate recognition of opioid overdose among heroin users. Int J Drug Policy. 2014;25(1): 166-170.

13. Kerr D, Kelly AM, Dietze P, Jolley D, Barger B. Randomized controlled trial comparing the effectiveness and safety of intranasal and intramuscular naloxone for the treatment of suspected heroin overdose. Addiction. 2009;104:2067-2074.

14. Merlin MA, Saybolt M, Kapitanyan R, et al. Intranasal naloxone delivery is an alternative to intravenous naloxone for opioid overdoses. Am J Emerg Med. 2010;28:296-303.

15. Sabzghabaee AM, Eizadi-Mood N, Yaraghi A, Zandifar S. Naloxone therapy in opioid overdose patients: intranasal or intravenous? A randomized clinical trial. Arch Med Sci. 2014;10:309-314.
16. Strang J, Bird SM, Parmar MK. Take-home emergency naloxone to prevent heroin overdose deaths after prison release: Rationale and practicalities for the N-ALIVE randomized trial. J Urban Health. 2013; 90(5):983-996.

17. Tobin KE, Sherman SG, Beilenson P, Welsh C, Latkin CA. Evaluation of the Staying Alive programme: training injection drug users to properly administer naloxone and save lives. Int J Drug Policy. 2009;20: 131-136.

18. Behar E, Santos GM, Wheeler E, Rowe C, Coffin PO. Brief overdose education is sufficient for naloxone distribution to opioid users. Drug Alcohol Depend. 2015;148:209-212.

19. Burris S, Norland J, Edlin B. Legal Aspect of Providing Naloxone to Heroin User in the United States. Temple Law School Working Papers. Int J of Drug Policy. 2001;12:237-248.

20. Seal KH, Thawley R, Gee L, et al. Naloxone distribution and cardiopulmonary resuscitation training for injection drug users to prevent heroin overdose death; a pilot intervention study. J Urban Health. 2005;82(2): 303-311.

21. Centers for Disease Control and Prevention (CDC). Community-based opioid overdose prevention programs providing naloxone - United States, 2010. MMWR Morb Mortal Wkly Rep. 2012;61:101-105.

22. Walley AY, Xuan Z, Hackman HH, et al. Opioid overdose rates and implementation of overdose education and nasal naloxone distribution in Massachusetts: interrupted time series analysis. BMJ. 2013;346:f174.

23. Substance Abuse and Mental Health Services Administration (SAMHSA). Federal guidelines for opioid treatment programs; 2015. Available from: http://store.samhsa.gov/shin/content/PEP15-FEDGUIDEOTP/PEP15FEDGUIDEOTP.pdf. Accessed January 8, 2015.

24. Substance Abuse and Mental Health Services Administration (SAMHSA). SAMHSA Opioid Overdose Toolkit: Five Essential Steps for First Responders. Available from: store.samhsa.gov/shin/content//SMA144742/Toolkit_FirstResponders.pdf. Accessed January 18, 2014.

25. Rudolph SS, Jehu G, Nielsen SL, Nielsen K, Siersma V, Rasmussen LS. Prehospital treatment of opioid overdose in Copenhagen - Is it safe to discharge on-scene? Resuscitation. 2011;82(11):1414-1418.

26. Wampler DA, Molina DK, McManus J, Laws P, Manifold CA. No deaths associated with patient refusal of transport after naloxone-reversed opioid overdose. Prehosp Emerg Care. 2011;15(3):320-324.

27. Vilke GM, Sloane C, Smith AM, Chan TC. Assessment for deaths in out-of-hospital heroin overdose patients treated with naloxone who refuse transport. Acad Emerg Med. 2003;10(8):893-896.
Open Access Emergency Medicine

\section{Publish your work in this journal}

Open Access Emergency Medicine is an international, peer-reviewed, open access journal publishing original research, reports, editorials, reviews and commentaries on all aspects of emergency medicine. The manuscript management system is completely online and includes a very quick and fair peer-review system, which is all easy to use.

\section{Dovepress}

Visit http://www.dovepress.com/testimonials.php to read real quotes from published authors. 